\title{
Waste Management Strategies in an Urban Setting Example from the Tamale Metropolis, Ghana
}

\author{
Ibrahim Issahaku, ${ }^{1}$ Frank K. Nyame, ${ }^{2}$ and Abdul Kadiri Brimah ${ }^{3}$ \\ ${ }^{1}$ School of Food and Health Sciences, Anglican University College of Technology, Nkoranza, Ghana \\ ${ }^{2}$ Department of Geology, University of Ghana, Legon, Accra, Ghana \\ ${ }^{3}$ Department of Chemistry, University of Ghana, Legon, Accra, Ghana
}

Correspondence should be addressed to Ibrahim Issahaku; asuro2006@yahoo.com

Received 18 August 2014; Revised 22 October 2014; Accepted 24 October 2014; Published 13 November 2014

Academic Editor: Enrico Davoli

Copyright (C) 2014 Ibrahim Issahaku et al. This is an open access article distributed under the Creative Commons Attribution License, which permits unrestricted use, distribution, and reproduction in any medium, provided the original work is properly cited.

\begin{abstract}
Tamale, one of the fastest growing cities in Ghana, is faced with daunting challenges in the management of Municipal Solid Waste. A corresponding increase of population and rising quality of life with high rates of resource consumption patterns have led to serious problems of high volumes of waste generated and costs involved. This research was therefore designed to focus on the Municipal Solid Waste Management strategies in Tamale, seeking to assess the performance of newly introduced tricycles for waste collection. The study employed the methodology of administration of questionnaire and interviews. The questionnaire and interviews revealed that there is a relationship in the level of education and how households stored their waste before disposal. There is also a close relationship in the household income level (residential class) and the use of covered plastic waste bins. Most households rated waste collection after the introduction of the tricycle as good followed by very good and satisfactory whilst none were of the view that waste collection was not good. Though there has been an improvement in waste collection after the introduction of the tricycles, there is the need for an integrated approach to waste management where all aspects of waste management are analyzed.
\end{abstract}

\section{Introduction}

Increasing waste generation rates due to population growth, changing lifestyles of people, development, and consumption of products with materials that are less biodegradable have led to the diverse challenges for Municipal Solid Waste Management (MSWM) in various cities of the world [1]. Cities are now grappling with the problems of high volumes of waste; high costs involved; the disposal technologies and methodologies; and the impact of wastes on the local and global environment. Municipal Solid Waste is linked with corresponding increase of both population and economy.

The Ghana Population and Housing Census conducted in the year 2000 showed that the population of Tamale $(293,881)$ grew by $48.8 \%$ between 1984 and 2000 . With a growth rate of $3.5 \%$, the population is expected to be 551,027 by 2025 . As one of the fastest growing cities in the country, Tamale is faced with daunting challenges in the management of Municipal Solid Waste (MSW). According to Ghana Districts [2], the
Refuse Generation Rate (RGR) in Tamale is about 150 tonnes per day. However, the city authorities can only take up to 7.5 tonnes of refuse per day leaving a backlog of 142.5 tonnes per day. This results in littering of waste in the city and dumping of refuse in drain channels thereby choking them. MSW in Tamale is at present managed through communal container system, door-to-door collection services, street litter bin systems, and evacuation of heaps.

According to a publication by United Nations Human Settlement Programme [3], inadequate funding is a challenge with waste management in Tamale. The amounts allocated by the Metropolitan Assembly from Internally Generated Funds and the District Assembly Common Fund for waste management are not sustainable.

In an attempt to mitigate some of these problems, the Tamale Metropolitan Assembly in 2006 contracted waste management services to Zoomlion Ghana Limited (ZGL), a private waste management company, who introduced, in addition to heavy duty trucks for collection of waste, tricycles 


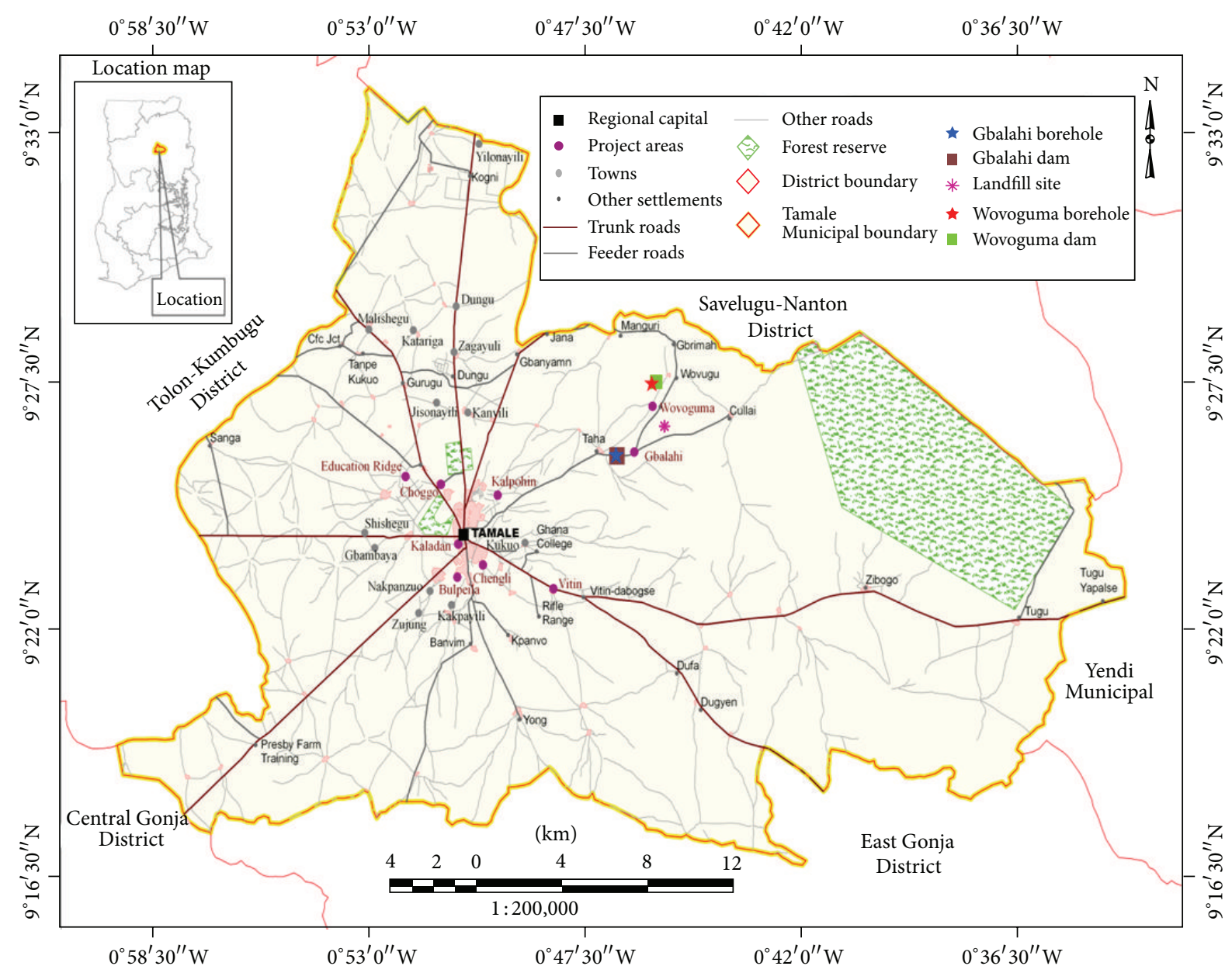

FIgUre 1: Map of Tamale showing study area.

locally called "Oboafo tricycle." There has, however, not been any study to assess the success or otherwise of waste management options after ZGL took over. In addition, there has not been any investigation with respect to the performance of the tricycles in waste collection and management, especially as to whether introduction of the tricycles may have resulted in improved waste management in the Metropolis.

In short, there has been little research in the Tamale metropolis on solid waste and management strategies. The key problems with solid waste disposal in Tamale principally relate to problems with indiscriminate dumping, increasing difficulties with acquiring suitable disposal sites, difficulties with conveyance of solid waste by road due to worsening traffic problems, and the lack of alternative transport options.

This research therefore focuses on the municipal solid waste management strategies in the Tamale metropolis, seeking to assess the performance of tricycles of ZGL in MSWM.

\section{Materials and Methods}

2.1. The Study Area. Tamale is one of the fastest growing cities in West Africa. Tamale is the capital town of the Northern
Region, one of ten in Ghana. It shares common boundaries with Savelugu/Nanton District to the north, Tolon/ Kumbungu District to the west, Central Gonja District to the south-west, East Gonja District to the south, and Yendi Municipal to the east (Figure 1). The Metropolis has been zoned into three submetros which include Tamale Central, Tamale North, and Tamale South.

2.1.1. Location and Size. Tamale is located within the Guinea Savannah belt between latitude $9^{\circ} 16^{\prime}$ and $9^{\circ} 34^{\prime}$ North and longitudes $0^{\circ} 36^{\prime}$ and $0^{\circ} 57^{\prime}$ West [2]. The size of Tamale is approximately $922 \mathrm{~km}$ sq.

2.2. Data Collection. Data were collected through visual inspection and preliminary field investigations, questionnaires survey, and face-to-face interviews. These are further discussed in the subsections below.

2.2.1. Household Survey. The Tamale metropolis is made up of about 48,975 households which serve as the target population of the study. A designed survey was administered to a sample of 180 households to give a confidence level of $93 \%$. A simple 
TABLE 1: Type of waste storage bin used.

\begin{tabular}{lcccc}
\hline Community & Plastic (\%) & Wooden basket (\%) & Metal (\%) & Total \\
\hline Kaladan (L.C) & 46.4 & 0.0 & 53.6 & 100 \\
Chengli (L.C) & 36.7 & 0.0 & 63.3 & 0.0 \\
Vittin Estates (H.C) & 97.0 & 3.0 & 40.0 & 100 \\
Bilpeila (L.C) & 60.0 & 0.0 & 23.3 & 100 \\
E. Ridge (M.C) & 73.3 & 3.3 & 50.0 & 100 \\
Choggu (L.C) & 42.9 & 7.1 & 38.0 & 100 \\
\hline Total & 59.6 & 2.4 & & 100 \\
\hline
\end{tabular}

H.C: high class residential area; M.C: middle class residential area; L.C: low class residential area.

Sources: derived from Tamale Municipal Assembly (2003), Medium Term Development Plan 2002-2005, and the Ghana 2000 Population and Housing Census Report.

and structured questionnaire was prepared and pretested. The questionnaire aimed to collect information about residents' demographic characteristics, attitudes towards waste, waste management behaviours, how much they are willing to pay for collection services, the performance of the tricycles by the Zoomlion Ghana Limited, and problems faced with the current management system. Due to anticipated variances of waste behaviours and incomes influenced by the type of locality [4], the surveys were conducted in households in $66.7 \%$ low class residential areas (Kaladan, Chengli, Bilpeila, and Choggu), $16.7 \%$ middle class residential areas (Education Ridge), and 16.7\% high class residential areas (Vittin Estate), where the percentages are representative of the proportionate population of people in the three localities.

The surveys took place as follows: after a random start at each location, every third house within the stratum was approached for inclusion in the sample. If there was no answer at the selected household, this was substituted with the next household. A door-to-door interview, conducted from December 2010 to January 2011, targeted questions to the head of the household or the spouse. In cases where neither was present, either the oldest child or a relative (over 15 years) was interviewed [4].

2.2.2. Solid Waste Management Program Operators' Survey. Another questionnaire was designed and administered to 25 members out of 123 of the waste collection crew for information on solid waste and management practices in the Tamale metropolis and the performance of the Tricycles, collection service availability, collection equipment and vehicles, distance travelled, collection points, collection fees, methods of collecting the fees, final disposal methods, location/type of dumping sites, and other relevant issues.

Face-to-face interviews were held with the Assistant Northern regional Director of Zoomlion Ghana Limited and the Head of the Solid waste division of the Tamale Waste Management Department. The department officials interviewed were those concerned with solid waste management at the respective institutions. Personnel consulted with respect to other sources of waste were also those responsible or conversant with solid waste management at the respective sources.

\section{Results and Discussion}

3.1. Introduction. In this chapter, the data gathered through administration and analysis of questionnaires (from the household solid waste generation and management, perceptions, attitudes, practices, and waste collection services) is presented. The results and discussion are presented as follows: assessment of household solid waste management; assessment of the waste management system; and performance of the tricycles in Tamale.

3.2. Household Solid Waste Management Practices in the Tamale Metropolis. The average household size (7.6 persons) in the Tamale Metropolis is relatively high in Ghana. This could be attributed to the higher level of illiteracy as indicated elsewhere [5]. Migration from surrounding towns and villages to the Metropolis also partly accounts for this observation [2]. As people move to the Metropolis in search of jobs and trading opportunities, many may stay with either relatives or friends in an effort to obviate the increasing cost of accommodation.

3.2.1. Type of Household Waste Storage Practice. There was variation on how households stored their waste before disposal. 92.2\% of households used waste bins which suggest that most of the people are concerned about hygiene and the need to keep the environment clean; $6.1 \%$ had no specific storage system and therefore disposed their waste directly at a disposal point after collection in the house. This probably accounts for littering of waste around some homes and in the communities. $1.7 \%$ stored waste within the house before disposal later. Of the waste bins that were used by respondents, approximately $59.6 \%$ were plastics and $38.0 \%$ metal (Table 1).

There were also differences in the way in which waste bins were used from one residential area to the other. $51.8 \%$ of the waste bins used were covered and $48.2 \%$ uncovered. Vittin Estate had the highest frequency (86.7\%) for covered bins and Chengli the highest (70.0\%) for uncovered bins (Figure 2). This indicates high use of covered bins from the high class residential area followed by the middle class residential area with low use in the low class residential areas. 


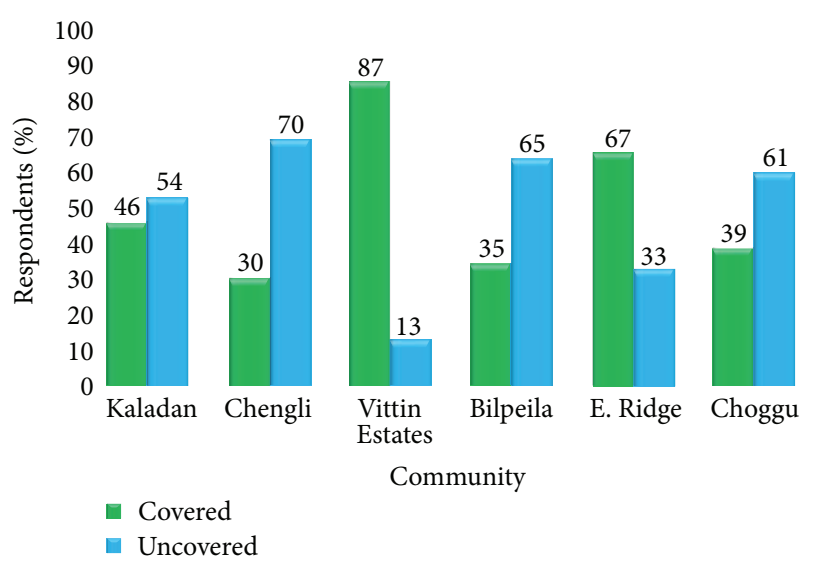

FIgURE 2: Type of waste storage bins used in various residential areas. Kaladan, Chengli, ..., and so forth same as in Table 1.

There is a relationship in the level of education and how households stored their waste before disposal. People become concerned with the broader objective of environmentally sound waste disposal only after adequate information and awareness [6]. This was observed on the variation in the type of waste storage system according to residential classes which indicate that majority of the residents in the high class and middle class residential areas used covered plastic waste bins whilst most households in the low class areas used uncovered metal waste bins. The high use of covered plastic waste bins in the high class residential area followed by the middle residential class with the low residential class the lowest indicates that the income level (residential class) is closely related to the type of waste management practice. In effect, the high and middle class residential areas are able to afford for customized waste bins with most of the residents in the low class residential areas not able to afford for waste bins and therefore resort to the use of old buckets and pans most of which are left uncovered and expose residents to communicable diseases. This is similar to what was discovered in Tamale by Osumanu [7] that high-wealth households stored their wastes in closed containers compared with medium-wealth and low-wealth households.

3.2.2. Household Waste Disposal. Solid waste from households in Tamale is swept and gathered into waste bins for disposal every morning and evening. Out of the people interviewed, approximately $64 \%$ of those sweeping, gathering, and disposing of all sorts of domestic waste are children under 18 years and females constitute $90.6 \%$ whilst males $9.4 \%$. This reflects the belief among the indigenes that house chores are for females and it is expedient that the young ones learn it before they grow to become adults.

In terms of frequency of waste disposal, $87.8 \%$ of the households in the Tamale Metropolis dispose of their waste every day; $9.4 \%$ store waste and dispose every other day, but $2.8 \%$ store and dispose every three days. For those using Community containers, $98 \%$ disposed of their waste every day and $2 \%$ every other day; $85.7 \%$ of those using Commercial refuse dump disposed of their waste every day with $14.3 \%$

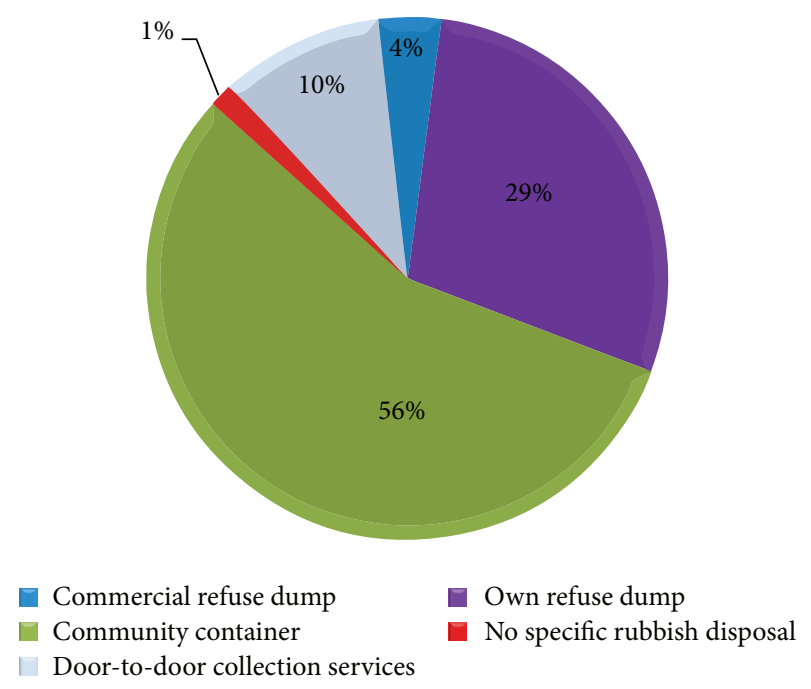

FIGURE 3: Means of household waste disposal.

every other day. However, all those who had their own refuse dump disposed of their waste every day and all those who use the door-to-door collection service stored their waste for two (72.2\%) to three (27.8\%) days before collection and disposal.

Majority of respondents in households (56\%) used the Community container system with few (1\%) having no specific refuse disposal system (Figure 3). This coupled with indiscriminate disposal contributes to the refuse littered around as seen in some areas within the Metropolis.

3.3. Assessment of the Waste Management Practices. Residents of the Tamale Metropolis receive waste management services from the Metropolitan Waste Management Department which works in partnership with Zoomlion Ghana Limited, a private waste management company in Ghana. Before the privatization of waste management in 2006, the Metropolitan Waste Management Department was the sole body responsible for waste in the metropolis.

\subsubsection{Pre-Zoomlion Household Access to Waste Management} Services. Residents in the Tamale Metropolis received waste management services from the Metropolitan Waste Management Department (MWMD) over the past ten years before the incorporation of Zoomlion Ghana Limited (ZGL). As a result of lack of adequate equipment, vehicles, and labour, commercial waste services were provided to the central business district of Tamale and the high class residential areas. Only selected parts of the middle class and few communities in the low class residential areas received commercial waste services. This shows why most households in the low class residential areas used their own refuse dump or community dump for waste disposal as indicated by Bilpeila (93\%) and Kaladan (50\%), respectively, with Vittin Estates having the highest (43\%) for community container. Also, it explains why most of the community containers were taken once every week and the community dumps cleared every three weeks to one month. 
Table 2: Preference for the type of waste disposal system.

\begin{tabular}{|c|c|c|c|c|c|}
\hline Community & Door-to-door (\%) & Community container (\%) & Community dump (\%) & Own (\%) & Total \\
\hline Kaladan & 36.7 & 56.7 & 0.0 & 6.7 & 100 \\
\hline Chengli & 50.0 & 50.0 & 0.0 & 0.0 & 100 \\
\hline Vittin Estates & 20.0 & 50.0 & 3.3 & 26.7 & 100 \\
\hline Bilpeila & 30.0 & 66.7 & 0.0 & 3.3 & 100 \\
\hline E. Ridge & 40.0 & 16.7 & 0.0 & 43.3 & 100 \\
\hline Choggu & 33.3 & 53.3 & 0.0 & 13.3 & 100 \\
\hline Total & 35.0 & 48.9 & 0.6 & 15.6 & 100 \\
\hline
\end{tabular}

Kaladan, Chengli, ..., and so forth same as in Table 1.

As a result of lack of access to commercial waste services, most low class residential areas (Bilpeila, Choggu, and Chengli) managed their own waste except Kaladan, a community located close to the central business district of Tamale where half of the households had access to waste services. All households in Education Ridge, a middle class residential area without access to commercial waste services, managed their own waste as found elsewhere [8].

Open burning was the common mode $(76 \%)$ of solid waste management for those who treated their own waste in Tamale. This could be due to easy access to land where households can openly dump their waste and burn in their backyard. Few others (24\%) buried their waste in their backyard.

On the perceptions of households on waste management services before the introduction of Zoomlion, most communities in the low class residential areas thought it was not good as a result of limited access to commercial waste services. None of the households in the high class residential area was of the view that waste management service before Zoomlion was good but most thought it was satisfactory. This could be due to the fact that they needed a more improved management system. Most households in the middle class residential area thought waste management services were satisfactory as they were doing it themselves.

3.3.2. Current Waste Management Services. Waste management services in Tamale are provided by the Metropolitan Waste Management Department (MWMD) and Zoomlion Ghana Limited (ZGL). The introduction of ZGL in waste management in Tamale has brought about the addition of more waste management equipment, vehicles and labour which has widened waste management services to include about $70 \%$ of the Metropolis. This has also brought about cleaning of the principal streets, lorry parks, dredging of gutters, door-to-door services, provision of dust bins in public places, and addition of more community containers with frequent collection in Tamale. Municipal Solid Waste in Tamale at present is managed through the communal container system, door-to-door collection services, street litter bin system, and community dumps.

The door-to-door waste collection service was carried out mainly in the high class residential areas as a result of their economic status. Most households in these areas are well to do and are able to afford and willing to pay for waste collection services. Also, these settlements are well planned and are easy to identify with accessed roads throughout. Door-to-door services are extended to those in the middle and low class residential areas upon special request to ZGL Tamale because most people in these areas are not willing to pay with some not able to afford for such services as found by Puopiel [9]. Also, most of the low class residential areas are not well planned making access to some households impossible. The door-to-door collection services are provided to approximately $11 \%$ households in the Tamale Metropolis.

Most households (49\%) in Tamale prefer the communal container system of waste collection due to the fact that it is free and available at all times contrary to what was found by Osumanu [7]. Majority of households in the low class residential areas preferred this system compared to any other residential class similar to what was discovered elsewhere [9]. Those in the high class residential areas also preferred it to any other waste collection systems. The door-to-door services follow with Chengli, a low class residential area having the most households (50\%) who preferred it as a way of lessening the effort of waste disposal (Table 2). A good number (40\%) of households in Education Ridge, a middle class residential area, also preferred the door-to-door collection services to lessen their burden of waste disposal. However, majority of households (43\%) in Education Ridge preferred their own waste management system to any other. This indicates that incineration which is most common in the area is preferred to any other waste management system.

Most households (76\%) in the Tamale Metropolis agreed that the current Municipal Solid Waste Management (MSWM) system was satisfactory as a result of the tremendous improvement in waste management over the past three years caused by the introduction of ZGL. Only few households $(10 \%)$ in the low class residential areas disagreed and some (1\%) strongly disagreed that the current MSWM system was satisfactory due to the fact that most of them do not have access to these services as indicated by Osumanu [7].

There is general willingness by households in Tamale to pay for waste collection services as majority of households thought it was good (38\%) followed by satisfactory (31\%) and not good (27\%). Majority of the communities in the low class residential areas were of the view that paying for waste collection services was not good due to the fact that most 
of them preferred the communal container system except Chengli where most preferred the door-to-door services. Households in the Tamale Metropolis were willing to pay between $\mathrm{GH} \propto 1$ and 15 per month for waste collection services. Most of the households were willing to pay between $\mathrm{GH} \propto 6$ and 10 per month followed by $\mathrm{GH} \propto 1$ and 5 per month and $\mathrm{GH} \propto 11$ and 15 per month. All respondents in Vittin Estate, a high class residential area, were willing to pay more than GH $\varnothing 5$ per month which could be due to their high income level. Majority of households in the low class residential areas were willing to pay between $\mathrm{GH} \propto 1$ and 5 per month as a result of their low income levels.

3.4. Assessment of the Performance of Tricycles. The tricycle waste collector concept ensures an effective and efficient collection of waste from communities, especially in those high density but low income communities where large and heavy waste collection trucks cannot access. The tricycles are principally assigned to collect waste from both commercial and residential areas including street sweepings, waste from bins along streets, waste from dredged gutters, market centers, lorry parks, and door-to-door.

A survey conducted on 25 out of 123 of the waste collectors revealed that $88 \%$ of the waste collectors had not worked in waste management before joining Zoomlion and have been in the company for approximately 3 years. A good number $(84 \%)$ of the waste collectors received training on waste management and safety within the company once every 6 months. This was to enable the collectors to keep themselves from the harmful effects of the waste which they collect daily. They were also provided with health and safety equipment such as hand gloves, nose masks, and overalls to help prevent them from contamination. But most of the waste collectors were observed to be commonly seen without nose masks and sometimes hand gloves this is due to the fact that these equipment easily perish and it normally takes a longer time for the management of ZGL to provide new ones. Hence, there is the need for measures to be taken to always replace the perished health and safety equipment in time.

Each of the waste collectors was assigned to collect waste daily from a specific area. Those using the motorized tricycle visited more waste collection points than those using the manual tricycle because, the motorized tricycle uses motor engine which makes it faster and of less human effort compared to the manual tricycle which is paddled by the waste collector. The mean quantity of waste carried by each waste collector is approximately 1,600 kilograms every day. This amounts to a mean quantity of 177,600 kilograms of waste collected by the tricycles and disposed into the containers a day.

The distance travelled by the manual tricycle to the nearest transfer station is less than $1 \mathrm{~km}$ due to the man power involved in riding it. Those using the motorized ones travel between 1 and $3 \mathrm{~km}$ because they are on engine and run faster. The minimum time ( $>10 \mathrm{~min})$ used by the motorist is more than that of the manual tricyclist $(<10 \mathrm{~min})$ because of the longer distance covered by the motorist. It takes 10 to $20 \mathrm{~min}$ for most of the waste collectors to travel to the nearest transfer station, meaning on average that about 40 to $80 \mathrm{~min}$ time is spent by most riders on travel to the transfer station. There is therefore the need for more transfer stations to be provided to enable faster hauling of waste and also less effort by waste collectors.

Most of the waste collectors were of the view the tricycle works well but begins to break down easily when old. The respondents gave some challenges they were facing using the tricycle as "the tricycle is old and easily breaks down," "riding it is tiresome," "you get weakened and exhausted after work," "the container is small and easily gets full," "the point of disposal is far," and "it takes a long time for safety equipment to be provided." These challenges given indicate the sort of frustration they normally go through in proving daily services. There is the need for the tricycles to be replaced every 3 years to aid a reliable, faster, and safe hauling of waste by the collectors. However, most of the waste collectors were able to carry out their daily schedules successfully.

$50 \%$ of the waste collectors were of the view that the performance of the tricycle was good followed by $25 \%$ very good, 20\% satisfactory, and 5\% not good. This shows that most of the waste collectors rate the tricycle high in performance and are satisfied using it in their daily delivery of waste services. However, the motorized tricycle was rated higher than the manual tricycle on performance. No one rated the motorized tricycle as not good indicating the preference by the waste collectors of the motorized to the manual tricycle. Therefore, there is the need for more motorized tricycles to be provided for happier and better waste service delivery by waste collectors in the Tamale Metropolis.

Most households rated waste collection after the introduction of the tricycle as good followed by very good and satisfactory whilst none were of the view that waste collection was not good. This indicates how the people of Tamale have embraced and appreciated the services rendered by the tricycle in waste management within the Metropolis and some therefore prefer its services. $64 \%$ of the respondents for the waste collectors strongly agree that the sanitation situation in the Tamale Metropolis has improved after the introduction of the tricycle whilst the rest (36\%) agree which gives an indication that there is no doubt about the contribution of the tricycle in waste management. The households also confirmed this by their response where none disagree that the sanitation situation in Tamale improved after the introduction of the tricycle.

On comparing the tricycle to trucks, most (48\%) of the waste collectors rated the tricycle good followed by very good (32\%) and satisfactory (20\%) indicating a general acceptance among the waste collectors that the performance of the tricycle in waste management was inevitable in Tamale.

3.5. Impact of the Improved Waste Management Service Introduced. Waste management service before the introduction of ZGL was provided to $30 \%$ of the Tamale Metropolis and this was within the central business district. About 7.5 tonnes of waste was collected and disposed by the WMD at the landfill site every day. 
The incorporation of ZGL into waste management resulted in a pragmatic improvement in waste collection, proper disposal, and an enlarged coverage of the Metropolis. About $70 \%$ of the Metropolis was now covered by the waste management system with the quantity of waste collected and disposed of at the landfill site rising greatly to 185.1 tonnes per day. This resulted in the Ghana Tourist Board rating Tamale as the cleanest city in Ghana in 2008 and also subsequently winning an award in 2010 from ZGL as the cleanest city in Ghana.

\section{Conclusion}

The study revealed that majority of households in Tamale use waste bins for storing solid waste. There is a relationship in the level of education and how households store their waste before disposal. This was observed on the variation in the type of waste storage system according to residential classes which indicate that majority of the residents in the high class and middle class residential areas used covered plastic waste bins whilst most households in the low class areas used uncovered metal waste bins. Also, income level (residential class) is closely related to the type of waste management practice.

The Metropolitan Waste Management Department (MWMD) in collaboration with Zoomlion Ghana Limited provides waste management services to about $70 \%$ of the people in the Metropolis with 30\% not covered. Most households in the Tamale Metropolis agree that the current Municipal Solid Waste Management (MSWM) services have tremendously improved over the past three years due to the introduction of the tricycles. There is a general willingness by households in Tamale to pay for waste collection services. The general performance of the tricycle appears satisfactory to many people. However, the motorized tricycle is rated higher than the manual tricycle in terms of performance.

4.1. Future Actions to Improve MSWM in Tamale. To improve upon the current solid waste management system, it is recommended here that the Tamale Metropolitan Assembly (TAMA) should intensify educational campaigns targeted at the middle and low class residents on sanitation especially waste management. This will help curb the menace of outbreak of communicable diseases and the use of unapproved waste bins for improved healthy living.

Also, the tricycle waste collector concept should be extended to all communities in the Tamale Metropolis since it has been successful and has helped improve tremendously solid waste management in the Tamale Metropolis. This should be backed with the provision of more motorized tricycles since the motorized tricycles have been found to be more efficient in waste collection to the manual tricycles.

More so, due to the general willingness of respondents to pay for waste management services in the Metropolis, the door-to-door services provided by the tricycles should be extended to every residential area in the Tamale Metropolis. The income levels of the residential areas should be considered for fees charged with subsidies for the low class residential areas since most of them cannot afford the current fees charged.

In addition, more communal containers should be provided to cover every residential area to deal with the issue of community dumping and open burning in the backyard and also to enable faster hauling of waste and less effort by waste collectors.

\section{Conflict of Interests}

The authors declare that there is no conflict of interests regarding the publication of this paper.

\section{Acknowledgment}

Heartfelt thanks go to the Zoomlion Ghana Limited for their support financially.

\section{References}

[1] M. Asase, E. K. Yanful, M. Mensah, J. Stanford, and S. Amponsah, "Comparison of municipal solid waste management systems in Canada and Ghana: a case study of the cities of London, Ontario, and Kumasi, Ghana," Waste Management, vol. 29, no. 10, pp. 2779-2786, 2009.

[2] Ghana Districts- A Repository of all the Districts in the Republic of Ghana, A Public-Private Partnership Programme between Ministry of Local Government and Rural Development and Maks Publications \& Media Services, 2006, http:// www.ghanadistricts.com/home/.

[3] United Nations Human Settlements Programme (UNHABITAT), Regional Technical Cooperation Division (Volume) 978-92-1-132182-1, Tamale, Ghana, 2009.

[4] I. A. Al-Khatib, M. Monou, F. A. Zahra, H. Q. Shaheen, and D. Kassinos, "Solid waste characterization, quantification and management practices in developing countries. A case study: Nablus district-Palestine," Journal of Environmental Management, vol. 91, no. 5, pp. 1131-1138, 2010.

[5] S. Agyei-Mensah, "Fertility transition in Ghana: looking back and looking forward," Population, Space and Place, vol. 12, no. 6, pp. 461-477, 2006.

[6] S. Peter, K. Wehrle, and J. Christen, "Conceptual framework for municipal solid waste management in low-income countries: urban management and infrastructure," Working Paper 40096, 1996.

[7] I. K. Osumanu, "Environmental concerns of poor households in low-income cities: the case of the Tamale Metropolis," GeoJournal, vol. 68, no. 4, pp. 343-355, 2007.

[8] A. A. Mensah, Physicochemical Characteristics of Solid Waste for Treatment Options: A Case Study of Kumasi, Ghana, Department of Civil Engineering, Kwame Nkrumah University of Science and Technology, 2010.

[9] F. Puopiel, Solid Waste Management in Ghana: The Case of Tamale Metropolitan Area, Kwame Nkrumah University of Science and Technology, Faculty of Planning and Land Economy, College of Architecture and Planning, 2010. 

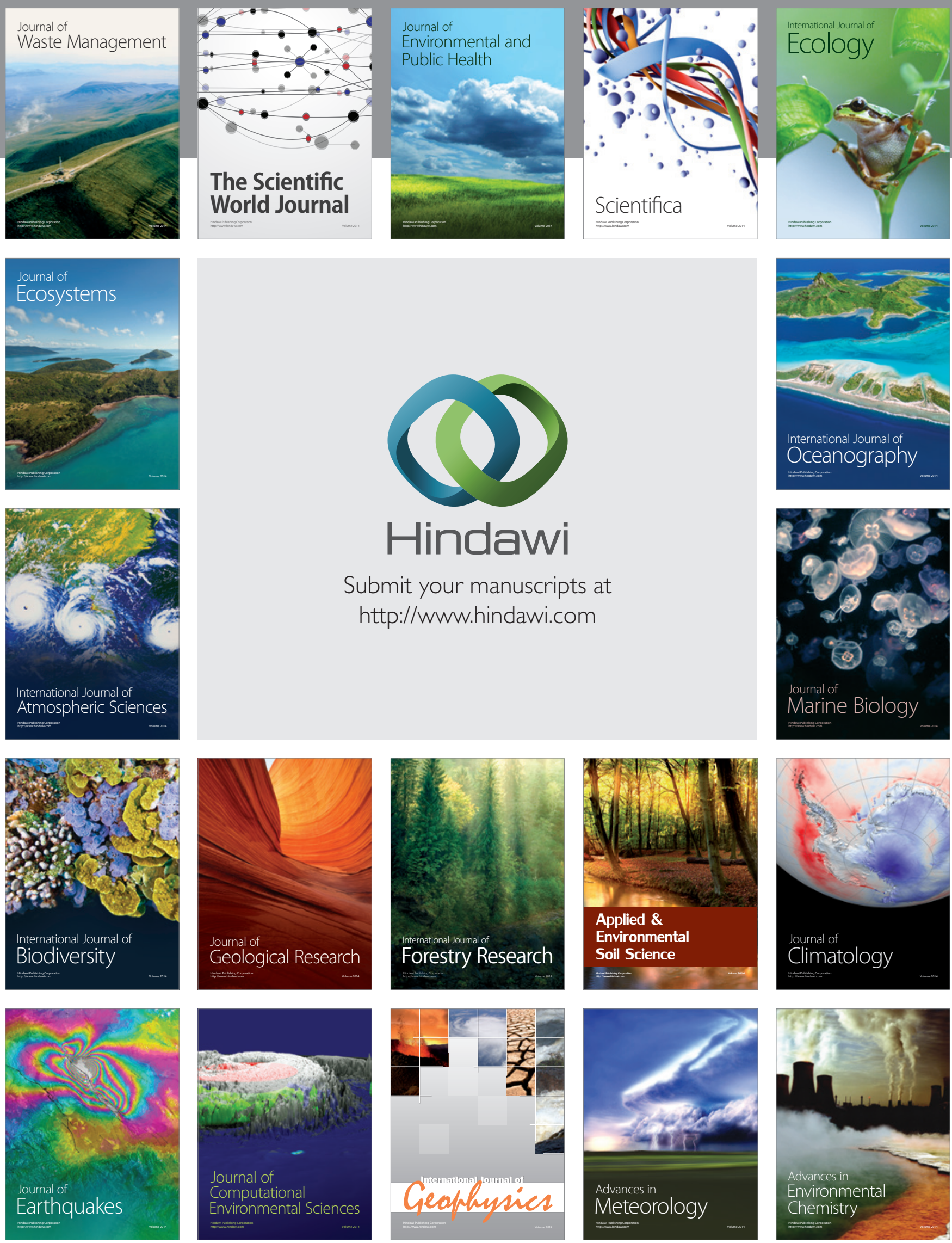